\title{
Epworth's Sleepiness Scale in Outpatients with Different Values of Arterial Blood Pressure
}

\author{
Migud Gus, Danie Nunes e Silva, Juliana Femandes, Caroline P. Curha, Geraldo Drudk Sant'Anna \\ Porto Alegre, RS - Brazil
}

\begin{abstract}
Objective - To compare sleepiness scores of the Epworth scale in patients with different levels of arterial pressure when undergoing outpatient monitoring within the context of clinical evaluation.
\end{abstract}

Methods - A total of 157 patients selected for outpatient monitoring of arterial pressure during hypertension evaluation were divided into 3 groups: group 1 - normotensive; group 2 - hypertensive; group 3 - resistant hypertensive. For analysis, values $\geq 11$ were considered as associated with respiratory disturbances during sleep.

Results - Seventeen (10.8\%) patients in group 1, 112 $(71.3 \%)$ in group 2 , and $28(17.8 \%)$ in group 3 , which was composed of aged, more severely hypertensive individuals, were analyzed. Groups were similar relative to sex and body mass index, but different in relation to systolic and diastolic pressure levels and age. Despite an absolute difference, no statistically significant difference occurred between Epworth scores and in the proportion of patients with values $\geq 11$ (5.9\% vs. $18.8 \%$ vs. $212.4 \%$; $P=0.37$ ). Despite the positive association between degree of sleepiness measured with the scale and the severity of the hypertension, no statistical significance occurred following control by age $(p=0.18)$.

Conclusion - A positive correlation exists between degree of sleepiness and hypertension severity. The absence of a statistical significance shown in the present study could be due to a beta type of error. Instruments that render this complaint into an objective finding could help in the pursuit of an investigation of respiratory disturbances $d u$ ring sleep in more severely hypertensive patients, and should therefore be studied better.

Keywords: hypertension, sleep apnea syndrome, Epworth sleepiness scale

Instituto de Cardiologia do Rio Grande do Sul/Fundação Universitária de Cardiologia

Mailing address: Miguel Gus - Unidade de Pesquisa do IC/FUC - Av. Princesa Isabel, 395 - 90620-001 - Porto Alegre, RS - Brazil - E-mail: mgus@ cardiol.br
Recent studies demonstrate the association between arterial hypertension and the obstructive sleep apnea syndrome diagnosed by polysomnography ${ }^{1,2}$. The VI Joint National Committee on Detection, Evaluation and Treatment of High Blood Pressure (VI JNC) points towards the obstructive sleep apnea syndrome as 1 of the 9 clinical situations responsible for resistant hypertension ${ }^{3}$. The presence of resistant arterial hypertension is not uncommon in the hypertensive population, affecting about $20 \%$ of patients ${ }^{4}$.

Polysomnography, the gold standard for diagnosing the obstructive sleep apnea syndrome, is a sophisticated examination, difficult to perform within a high prevalence context like that of hypertension. Thus, the identification of clinical parameters associated with this syndrome would be an ideal screening procedure for identifying hypertensive individuals who should undergo polysomnography.

Sleepiness during the day is a clinical parameter essential for the suspicion of a diagnosis of the obstructive sleep apnea syndrome. The Epworth sleepiness scale is an easy-to-administer questionnaire incorporating the possibility of using this complaint as an objective parameter. Clinical studies of polysomnography have demonstrated that values $\geq 11$ are associated with sleep disturbances, including the obstructive sleep apnea syndrome ${ }^{5,6}$.

The objective of the present study was the comparison between differences in the sleepiness score of patients with different degrees of systemic arterial hypertension undergoing outpatient monitoring of arterial pressure within the context of clinical evaluation.

\section{Methods}

Patients aged over 18 years were selected from subjects seen for outpatient monitoring of arterial pressure during their evaluation at the Serviço de Hypertensão do Instituto de Cardiologia/Fundação Universitária de Cardiologia do Rio Grande do Sul between June of 1999 and July of 2000. The possibility of the presence of sleep disturbances was determined based on telephone contacts in which patients indicated having a history of snoring and the Epworth 
sleepiness scale composed of questions on the possibility of napping during 8 different situations. Patients rated each question on a scale of 0 to 3 . The maximum value attainable was $24^{5,6}$ (Table I). Data concerning the use of antihypertensive medication, and the weight and height of the patients were also collected. The Spacelab 90702 apparatus with 3 and 4 hourly checks during sleep and wakefulness respectively was used for outpatient monitoring of arterial pressure. Systolic and diastolic pressure averages were taken for analyses over 24 hours, and a nocturnal (11:00 PM to 7:00 AM) decrease in pressure was also noted; examinations were accepted when at least 1 valid measurement had been taken every hour.

For comparisons, patients were divided into 3 groups: group 1 (normotensive) - patients with a 24-hour systolic average $<135 \mathrm{mmHg}$ and a diastolic average $<85 \mathrm{mmHg}$, not using medication; group 2 (hypertensive) - patients with a 24hour systolic average $<135 \mathrm{mmHg}$ and a diastolic $<85 \mathrm{mmHg}-$ using antihypertensive medication or systolic or diastolic averages $\geq 135 / 85 \mathrm{mmHg}$, or both, using up to 1 antihypertensive medication; and group 3 (resistant hypertensive) patients with systolic or diastolic averages $\geq 135 / 85 \mathrm{mmHg}$ or both, using at least 2 antihypertensive medications. The 3 groups were compared relative to age, sex, body mass index, snoring history, and pressure values checked by outpatient monitoring of arterial pressure and also values on the sleepiness scale, as well as frequency of individuals having Epworth scores $\geq 11$ or a history of snoring.

Comparisons were made with the ANOVA test for continuous variables, using Bonferroni's test to identify which groups differed from each other. Differences between category variables were analyzed with the $\chi^{2}$ test. Logistic regression models were created, based on theoretical presuppositions by the authors, to evaluate the isolated effect of analyzed variables relative to the occurrence of hypertension or resistant hypertension.

\section{Results}

Two hundred thirty-one consecutive patients undergoing outpatient monitoring of arterial pressure were included. Six were excluded due to technical examination problems, and 60 due to difficulties in the obtained interview data. A total of 157 patients ( $70.4 \%$ of the total sample) were analyzed, $17(10.8 \%)$ from group $1,112(71.3 \%)$ from group 2 , and $28(17.8 \%)$ from group 3 . Table II demonstrates that this

\begin{tabular}{|l|}
\hline \multicolumn{1}{|c|}{ Table I - Epworth sleepiness scale } \\
\hline 1. Seated reading ( ) \\
2. Watching TV ( ) \\
3. Seated, inactive in a public place ( ) \\
4. As automobile passenger for one hour without braking ( ) \\
5. Lying down, resting in the afternoon when circumstances permit ( ) \\
6. Seated, talking to someone ( ) \\
7. Calmly seated after lunch without use of alcohol ( ) \\
8. In a car stopped for a few minutes in the traffic ( ) \\
Total ..........
\end{tabular}

\begin{tabular}{|c|c|c|c|c|}
\hline \multicolumn{5}{|c|}{$\begin{array}{l}\text { Table II - Characteristics of patients according to the severity of } \\
\text { arterial systemic hypertension - means } \pm \text { SD or \% }\end{array}$} \\
\hline Variable & $\begin{array}{l}\text { Group } 1 \\
(\mathrm{~N}=17)\end{array}$ & $\begin{array}{l}\text { Group } 2 \\
(\mathrm{~N}=112)\end{array}$ & $\begin{array}{l}\text { Group } 3 \\
(\mathrm{~N}=28)\end{array}$ & $\mathrm{P}$ \\
\hline Males (\%) & 41.2 & 38.4 & 39.3 & 0.97 \\
\hline Age (years) & $45.5 \pm 14.3$ & $53.4 \pm 11.2$ & $56.7 \pm 11.9 * *$ & 0.012 \\
\hline BMI $\left(\mathrm{kg} / \mathrm{m}^{2}\right)$ & $26.8 \pm 5.6$ & $26.6 \pm 3.8$ & $27.4 \pm 4.3$ & 0.62 \\
\hline SAP over $24 \mathrm{~h}(\mathrm{mmHg})$ & $121.8 \pm 5.4$ & $134.4 \pm 13.6$ & $143.2 \pm 15.3^{*}$ & $<0.001$ \\
\hline DAP over $24 \mathrm{~h}(\mathrm{mmHg})$ & $75.7 \pm 5.0$ & $83.0 \pm 9.6$ & $85.9 \pm 13.6^{* *}$ & 0.005 \\
\hline $\begin{array}{l}\text { Nocturnal systolic } \\
\text { decrease }^{\delta}\end{array}$ & $10.7 \pm 7.8$ & $9.7 \pm 7.3$ & $4.7 \pm 10.1 * * *$ & 0.008 \\
\hline $\begin{array}{l}\text { Nocturnal diastolic } \\
\text { decrease }^{\delta}\end{array}$ & $15.4 \pm 9.3$ & $14.0 \pm 8.7$ & $9.7 \pm 11.0$ & 0.06 \\
\hline \multicolumn{5}{|c|}{$\begin{array}{l}* \text { Group } 1 \text { vs. } 2 ; 1 \text { vs } 3 ; 2 \text { vs } 3-* * \text { group } 1 \text { vs } 2 ; 1 \text { vs. } 3 \text { - *** group } 1 \text { vs. } 3 \text {; } \\
2 \text { vs. } 3 ; \delta \text { percentage points; SD-standard deviation; BMI- body mass index; } \\
\text { SAP-systolic arterial pressure; DAP-diastolic arterial pressure. }\end{array}$} \\
\hline
\end{tabular}

last group was made up of significantly older subjects, more severely hypertensive, and with a reduced nocturnal systolic decrease. Groups did not differ in relation to sex and body mass index. Table III compares sleepiness scale scores and snoring frequency in the 3 groups. No difference in the percentages of snoring occurred, but although not attaining statistical significance, a linear increase in the averaged Epworth score and the frequency of subjects with higher scores (Epworth $\geq 11$ )-existed when groups 1, 2, and 3 were compared. Table IV presents a logistic regression model in which the presence of systemic arterial pressure (resistant or not) was included as the dependent variable. Age was significantly associated with the diagnosis of systemic arterial hypertension. A tendency existed towards statistical significance relative to the presence of an Epworth score $\geq 11$. Other models that included resistant arterial hypertension as dependent variable had similar results.

\section{Discussion}

Obstructive sleep apnea syndrome is a disturbance characterized by recurring episodes of respiratory flow arrest during sleep ${ }^{7}$, affecting about $4 \%$ of men and $2 \%$ of women $^{8}$.

Several recent studies have strengthened indications

\begin{tabular}{|lcccc|}
\hline \multicolumn{5}{|c|}{$\begin{array}{c}\text { Table III - Sleep disturbances according to the severity of systemic } \\
\text { arterial hypertension-means } \pm \text { SD or \% }\end{array}$} \\
\hline Variable & $\begin{array}{c}\text { Group 1 } \\
(\mathrm{N}=17)\end{array}$ & $\begin{array}{c}\text { Group 2 } \\
(\mathrm{N}=112)\end{array}$ & $\begin{array}{c}\text { Group 3 } \\
(\mathrm{N}=28)\end{array}$ & $\mathrm{P}$ \\
& 64.7 & 59.8 & 60.7 & 0.40 \\
\hline Snoring (\%) & $4.7 \pm 3.9$ & $\begin{array}{c}6.0 \pm 4.8 \\
\text { Epworth score }(\%)\end{array}$ & $\begin{array}{c}7.0 \pm 5.7 \\
21.4\end{array}$ & 0.29 \\
Score above 11 (\%) & 5.9 & 18.8 & 21.4 \\
\hline
\end{tabular}

\begin{tabular}{|c|c|c|c|c|}
\hline \multicolumn{5}{|c|}{$\begin{array}{l}\text { Table IV - Model of the logistic regression that includes the diagnosis } \\
\text { of arterial systemic hypertension as the dependent variable }\end{array}$} \\
\hline Explanatory variable & B & $\operatorname{Exp}(\mathrm{B})$ & IC $(95 \%)$ & $\mathrm{P}$ \\
\hline Age (continuous variable) & $0.05 \pm 0.02$ & 1.05 & $1.01-1.10$ & 0.008 \\
\hline Score $\geq 11$ & $1.4 \pm 1.07$ & 4.7 & $0.51-33.4$ & 0.18 \\
\hline
\end{tabular}


that this syndrome may cause arterial hypertension ${ }^{4,9-13}$. It is understood that respiratory sleep disturbances have components of increased sympathetic activity, decreased reflex baroreceptor sensitivity, and vascular hyper-responsiveness ${ }^{14}$. Carlson et al ${ }^{15}$ demonstrated that patients with the obstructive sleep apnea syndrome have a significant increase in sympathetic muscle activity when compared with controls during wakefulness. An increase in plasma levels of norepinephrine associated with systolic arterial pressure was observed, suggesting a correlation between these factors and the development of the cardiovascular complications of obstructive sleep apnea syndrome ${ }^{16}$. The same authors pointed towards the decreased sensitivity of the baroreflex stimulus consequent to increased sympathetic activity as a possible mechanism for the development of sustained systemic arterial hypertension in patients with obstructive sleep apnea syndrome ${ }^{17}$.

The recently published 4-year follow-up of 709 patients from an American working community supplied data for a first cohort study evaluating the obstructive sleep apnea syndrome as a risk factor for the development of arterial hypertension ${ }^{2}$. A positive association, controlled by confusion factors, with a relative risk of 2.89 (IC 1.49-5.64) was found in individuals with an apnea/hypopnea index ${ }^{3} 15$.

Another recent study ${ }^{1}$, with a transversal design performed with a sample of 6,841 patients, similarly demonstrated an association between an apnea/hypopnea index diagnosed by home polysomnography and hypertension. Specific analyses demonstrated that this finding was independent of obesity, sex, or age.

Despite these findings, this topic has not been fully appreciated by the majority of doctors active in the area of hypertensive disease ${ }^{18,19}$. An explanation for this fact could be the difficulty in the diagnosis of obstructive sleep apnea syndrome. The gold standard for its identification is polysomnography, which permits the monitoring of stages of sleep, oxygen saturation, and respiratory patterns, and quantifies the number of apneas and hypopneas during sleep by the apnea/hypopnea index ${ }^{20}$. However, polysomnography is an expensive examination, demanding patient cooperation, a capable professional, and a specific laboratory ${ }^{8,21}$.

A clinical interview during the screening of patients with a suspicion of obstructive sleep apnea syndrome would be a useful tool, because it could be used by any medical professional. Hoffstein et al ${ }^{15}$ demonstrated that a clinical result alone would not be sufficient to diagnose obstructive sleep apnea syndrome, only attaining a $60 \%$ sensitivity, and a $63 \%$ specificity. The Epworth sleeping scale was considered by Johns ${ }^{6}$ as a form of objective evaluation of a complaint of sleepiness. A significant correlation between values $\geq 11$ and sleep disturbances, among which is the obstructive sleep apnea syndrome, was found. Polysomnography was used as the gold standard in this clinical investigation. The more severe the hypertension is we may assume that differences will exist in the Epworth values and the proportion of individuals with values $\geq 11$ if an association between obstructive sleep apnea syndrome and systemic arterial hypertension exists and an association between values on the sleepiness scale and the obstructive sleep apnea syndrome as diagnosed by polysomnography also exists. This finding would indicate that the questionnaire is a promising instrument for the evaluation of hypertension, because it could be an indirect indicator of the presence of a respiratory sleep disturbance.

The 3 groups compared were different concerning the severity of the hypertension, a positive association existing between the severity of sleepiness and the severity of systemic arterial hypertension, independently of other confusing factors like age. The lack of statistical significance could be a consequence of a low power of the sample or equally of the limitations of the questionnaire to indicate hypertensive carriers of the obstructive sleep apnea syndrome within the clinical context.

The frequency of snoring, a symptom often associated with the obstructive sleep apnea syndrome, is to be noted in the present sample; it confirms the hypothesis that hypertensives are individuals with a higher prevalence of respiratory disturbances during sleep. The above-cited results of the study with American workers ${ }^{2}$ showed a prevalence of $20 \%$ of snoring in the general population, a value much below the $60 \%$ of the present work. However, a similarity in numbers between the 3 groups does not indicate that this is a reliable clinical parameter for indicating the presence or not of the obstructive sleep apnea syndrome within the context of hypertensive individuals.

Other methods less complex than polysomnography have been tested as a way of screening patients for a deeper investigation of the obstructive sleep apnea syndrome. Some workers ${ }^{22,23}$ defend the use of pulse oximetry to this effect.

We conclude that it remains a challenge to identify simpler clinical or complementary methods to aid in the diagnosis of the obstructive sleep apnea syndrome in the routine management of hypertensives. The research of the degree of sleepiness among patients with more severe hypertension could help in proposing the use of more definitive diagnostic procedures like polysomnography.

\section{References}

1. Nieto JF, Young TB, Lind BK, et al. Association of sleep- disordered breathing, sleep apnea, and hypertension in large community - based study. JAMA 2000; 283: 1829-36.

2. Peppard PE, Young T, Palta M, Skatrud J. Prospective study of the association between sleep-disordered breathing and hypertension. N Eng J Med 2000; 342: $1379-84$

3. The Sixth Report of the Joint National Committee on Prevention, Detection, Evaluation, and Treatment of High Blood Pressure. Arch Intern Med 1997; 157: 2413-46. 
4. Australian National Blood Pressure Study Management Committee. The Australian therapeutic trial in mild hypertension. Lancet 1980; 1: 1261-7.

5. Johns MW. A new method for measuring daytime sleepiness: the Epworth sleepiness scale. Sleep 1991; 14: 540-5.

6. Johns MW. Reliability and factor analysis of the Epworth sleepiness scale. Sleep 1992; 15: 376-81.

7. Hudgel DW. The role of upper airway anatomy and physiology in obstrutive sleep apnea. Clin Chest Med 1992; 13: 383-98.

8. Young T, Palta M, Dempsey J, et al. The ocurrence of sleep-disordered breathing among middle-aged adults. N Eng J Med 1993; 328: 1230-5.

9. Koskenvuo M, Partinen M, Sarna S, et al. Snoring as a risk factor for hypertension and angina pectoris. Lancet 1985; 20: 893-6.

10. Lavie P, Ben-Yosef R, Rubin AE. Prevalence of sleep apnea syndrome among patients with essential hypertension. Am Heart J 1984; 108: 373-6.

11. Fletcher EC, DeBehnke RD, Lovoi MS, Gorin AB. Undiagnosed sleep apnea in patients with essential hypertension. Ann Intern Med 1985; 103: 190-5.

12. Williams AJ, Houston D, Finberg S, et al. Sleep apnea syndrome and essential hypertension. Am J Cardiol 1985; 55: 1019-22.

13. Fletcher EC, Lesske J, Qian W, Miller III CC, Unger T. Repetitive, episodic hypoxia causes diurnal elevation of blood pressure in rats. Hypertension 1992; 19: 555-61

14. Young TB, Peppard P, Palta M, et al. Population-based study of sleep-disordered breathing as a risk factor for hypertension. Arch Intern Med 1997; 157: 1746-52.
15. Hoffstein V, Szalai JP. Predictive value of clinical features in diagnosing obstructive sleep apnea. Sleep 1993; 16: 118-22.

16. Carlson JT, Hedner J, Elam M, et al. Augmented resting sympathetic activity in awake patients with obstrutive sleep apnea. Chest 1993; 103: 1763-8.

17. Carlson JT, Hedner JA, Sellgren J, Elam M, Wallin BG. Depressed baroreflex sensitivity in patients with obstructive sleep apnea. Am J Respir Crit Care Med 1996; 154: 1490-6.

18. Silverberg DS, Oksenberg A, Iaina A. Sleep related breathing disorders are common contributing factors to the production of essencial hypertension but are neglected, underdiagnosed, and undertrreated. Am J Hypert 1997; 10: 1319-25.

19. Silverberg D, Oksenberg A, Iaina A. The joint committee on prevention, detection, evaluation, and treatment of high blood pressure and obstructive sleep apnea: let their silence not be matched by the silence of the ordinary physician. Arch Intern Med 1998; 158: 1272-3.

20. American Thoracic Society. Indications and standards for cardiopulmonary sleep studies. Am Rev Respir Dis 1989; 139: 559-68.

21. Strollo PA, Rogers RM. Obstrutive sleep apnea. NEngl J Med 1996; 101: 251-6.

22. Chiner E, Signes-Costa J, Arriero JM, et al. Nocturnal oximetry for diagnosis of sleep apnoea hypopnoea syndrome: a method to reduce the number of polysomnographies. Thorax 1999; 54: 968-71.

23. Lévy P, Pépin JL, BrambillaC, et al. Accuracy of oximetry for detection of respiratory disturbances in sleep apnea syndrome. Chest 1996; 109: 395-9. 